\title{
Brincando na educação infantil - ensinar e aprender com retóricas lúdicas
}

\section{Playing in childhood education - teaching and learning with playful rhetoric}

\section{Jugar en la educación de la primera infancia- enseñar y aprender con retóricas lúdicas}

\author{
Cleomar Ferreira Gomes ${ }^{1}$
}

DOI: http://dx.doi.org/10.20435/serie-estudos.v26i56.1267

\begin{abstract}
Resumo: O ensaio em tela é fruto de uma investigação sobre retóricas lúdicas, narradas por professoras no cotidiano da Educação Infantil. Com um questionário semiestruturado, aplicado em seus loci de trabalho, identificamos a noção que as professoras têm de brincadeiras, o método que utilizam para atividades lúdicas no ambiente escolar, bem como as narrativas que organizam tais atividades, para algum resultado positivo na educação de crianças pequenas. Supomos apropriado considerar aquilo que alguns teóricos dos termos brinquedos e brincadeiras relevam como válidos pela pena da ciência. Foi muito rico para pesquisadores e professoras saber como elas lidam com esses conceitos e como aproveitam esses conhecimentos adquiridos nos cursos de formações específicas e estudos para, na intervenção, auferir algum resultado prático. Formulamos algumas questões que pudessem cercar esses conhecimentos no modus operandi de cada uma dessas professoras. As respostas revelaram que os discursos são favoráveis à entrada de brinquedos, jogos e brincadeiras no espaço escolar porque estimulam o curso natural do desenvolvimento das crianças. De modo particular, foi possível analisar as formas de envolvimento e as intervenções naquilo que narram como percepções, noções e mesmo intervenções pedagógicas, que melhor representam as funções estéticas e pedagógicas das brincadeiras e dos brinquedos quando se subsumem nos espaços de escolarização.
\end{abstract}

Palavras-chave: educação infantil; alegorias brincantes; intervenção pedagógica.

\begin{abstract}
This paper is the result of an investigation into ludic rhetoric, narrated by teachers in the daily life of Childhood Education. With a semi-structured questionnaire, applied in their work loci, we identified the notion that teachers have to play, the method they use for playful activities in the school environment, as well as the narratives that organize such activities, to some positive result in the education of young children. We assume it is appropriate to consider what some theorists of the terms toys and games consider to be valid for the penalty of science. It was very rich for researchers and teachers to know how they deal with these concepts and how they take advantage of this knowledge acquired in the courses of specific formations and studies to earn,
\end{abstract}

1 Universidade Federal de Mato Grosso (UFMT), Cuiabá, Mato Grosso, Brasil. 
in the intervention, some practical results. We formulate some questions that could surround this knowledge in the modus operandi of each of these teachers. The answers revealed that the discourses are favorable to the entry of toys, games, and pranks in the school space because they stimulate the natural course of children's development. In particular, it was possible to analyze the forms of involvement and interventions in what they narrate as perceptions, notions, and even pedagogical interventions, which best represent the aesthetic and pedagogical functions of games and toys when topped in the spaces of schooling.

Keywords: childhood education; playing allegories; pedagogical intervention.

Resumen: El ensayo en pantalla es el resultado de una investigación sobre retóricas lúdicas, narrado por maestros en la vida cotidiana de la educación infantil. Con un cuestionario semi-estructurado, aplicado en sus loci de trabajo, identificamos la noción de que los profesores tienen que jugar, el método que utilizan para las actividades lúdicas en el ambiente escolar, así como las narrativas que organizan tales actividades, para algunos resultados positivos en la educación de los niños pequeños. Suponemos que es apropiado considerar lo que algunos teóricos de los términos juguetes y juegos infantiles consideran válido para la pena de la ciencia. Fue muy rico para los investigadores y profesores saber cómo se ocupan de estos conceptos y cómo se aprovechan de este conocimiento adquirido en los cursos de formaciones específicas y estudios para obtener, en la intervención, algunos resultados prácticos. Formulamos algunas preguntas que podrían rodear este conocimiento en el modus operandi de cada uno de estos maestros. Las respuestas revelaron que los discursos son favorables a la entrada de juguetes, juegos y travesuras en el espacio escolar porque estimulan el curso natural del desarrollo de los niños. En particular, fue posible analizar las formas de implicación e intervenciones en lo que narran como percepciones, nociones e incluso intervenciones pedagógicas, que mejor representan las funciones estéticas y pedagógicas de juegos y juguetes cuando son cubiertos en los espacios de escolarización.

Palabras clave: educación infantil; jugando con alegorías. intervención pedagógica.

\section{BRINQUEDO E BRINCADEIRA, DA IMPORTÂNCIA DAS NOÇÕES}

Esses vocábulos, no terreno da escola de crianças pequenas, traduzem-se como atividades que se situam, preferencialmente, no campo simbólico, como diz Château (1987):

Se as crianças lutam, é menos, frequentemente, por raiva do que porque não podem fazer feio e recuar. Nessa batalha, a hostilidade pode ser mínima ou até nula, e os dois adversários não lutam para se machucarem, mas para se testarem mutuamente. (CHÂTEAU, 1987, p. 28).

No solo paradigmático dos jogos de faz de conta. Eles nascem de uma força criativa que tem o ser humano, as crianças por excelência, de exercer a sua rubrica lúdica, isto é, uma capacidade natural de fazer coisas, manipular objetos, produzir fatos e de inventar histórias que põem em ação um preenchimento do tempo de sua existência subjetiva e social. 
Essas atividades devem ter a preocupação primordial de ajudar as crianças a estimularem-se para sua criatividade, à aprendizagem das regras sociais e a se libertarem dos "horrores do mundo de gigantes", como prefere Benjamin (1984, p. 64), porque esse mundo é feito de obrigações pesadas demais para a cultura infantil que tem outra realidade para dar conta. É bom lembrar que essa criança a que se refere esse autor se materializaria numa "criança ideal", e não nas "crianças reais" que conhecemos, sobretudo aquelas dos países mais empobrecidos, onde, desde cedo, a sua infância lúdica é esboroada pelas dificuldades existenciais (fome, escolarização precária, insalubridade, riscos sociais, maus-tratos), e que doravante serão impelidas aos apelos do mundo do trabalho precoce.

\section{AS BRINCADEIRAS}

É bom repetir que o termo brincadeira não existe noutra cultura linguística como nós o utilizamos por aqui. Muitas vezes, confunde-se com a palavra ludicidade, que não consegue separar aquilo que dissimula, que simboliza e o que dá prazer. A qualidade que tem um objeto (brinquedo) ou uma atividade (brincadeira) é que faz despertar um estado lúdico, a espontaneidade, o senso de humor e a alegria. É uma atividade livre, instável, voluntária e não sujeita a ordens externas ao seio da própria brincadeira. O professor de crianças pequenas deve saber que é precisamente em tal fato que reside sua espontaneidade ou aquilo que apregoa Huizinga (1990), como sendo a sua primeira característica.

Desse modo, poderíamos acentuar que a brincadeira é a ação de brincar, uma atividade espontânea, composta de regras flexíveis, que carrega a função precípua de entreter e que escorre em tempos e espaços à escolha do brincador, de caráter atemporal, sendo mais exclusiva da Cultura Infantil.

\section{DOS BRINQUEDOS E DE CRIANÇAS}

Cascudo (1988, p. 146), com seu dicionário do folclore brasileiro, apresenta dois diferentes sentidos para brinquedo. Num primeiro, tanto brinquedo como brincadeira são sinônimos de jogos, rondas, divertimentos tradicionais infantis, cantados, declamados, ritmados ou não, de movimento. Num segundo, o brinquedo é um objeto material para brincar - carro, arco, boneca, soldados, papagaio, figuras -, assim como a própria ação de brincar - brinquedo de dona de 
casa, de cabra-cega, de galinha-gorda, de chicote-queimado. Como se vê nessas duas acepções, há, por um lado, o dinamismo de uma atividade e, doutra parte, o leiaute de um objeto em que vigora a experiência lúdica.

Algumas informações de Cascudo (1988) nos pareceram servir, em especial, para o assunto do presente ensaio. A primeira diz respeito às brincadeiras infantis mais preferidas. No dizer do autor, essas brincadeiras mais populares (CASCUDO, 1988, p. 146) são as mais universais e de livre movimentação individual. Essas brincadeiras dificilmente desaparecem: são das mais admiráveis constantes sociais, transmitidas por via oral, abandonadas numa geração e reerguidas na outra, numa sucessão ininterrupta de movimento e de canto. A segunda diz respeito às menos preferidas das crianças. "São as que restringem o direito de alguma improvisação no gesto e na carreira. Esgotam rapidamente o desejo de brincar e monotonizam o grupo" (CASCUDO, 1988, p. 146). São brincadeiras que não promovem a excitação, não têm uma força ou vivacidade tal que possam absorver por completo o brincador. Seriam, numa linguagem própria de criança, aquelas brincadeiras sem graça, xoxas ou "chatas".

Para autores da língua francesa como Brougère (1995) e Manson (2002), por exemplo, a noção de brincadeira - de "jogo" - precisa ser relativizada quando se pretende pesquisar sobre o assunto. Brougère (1995) recomenda partir do princípio de que jogo - a brincadeira - "é uma palavra complexa e que é preciso às vezes, um consenso no que é". Há pesquisadores que se interessam pela utilização da palavra jogo, "pelo discurso sobre o jogo", por uma reflexão sobre a palavra jogo, seu campo semântico, e, portanto, o "centro do trabalho" é a significação mais do que o jogo em si. O autor inclui-se entre aqueles que não se interessam pelo que ele denomina como "retórica" sobre o jogo, à guisa do que faz Sutton-Smith (1997) em sua obra The ambiguity of play. Para Brougère (1995), essa reflexão é secundária, quando nos dirigimos às atividades endereçadas às crianças. Mas podemos nos interessar pelo uso da palavra, mostrando o que as pessoas chamam de jogo, o que os mais velhos e as crianças chamam de jogo, isto é, pensar a questão da palavra jogo, mas em relação ao que consideram aqueles que brincam e aqueles que não brincam. São elas que podem dominar a resposta, não o pesquisador. Pode ser, explica Brougère (1995), que venhamos a descobrir que é importante o que é chamado de jogo (brincadeira), mas isso se descobrirá no campo, nas observações, na conversação. Num primeiro tempo, o que interessa é ver o que as crianças fazem. 
Outro autor que alerta o pesquisador sobre as armadilhas das categorizações ou conceitos iniciais "muito fixos" - os pré-conceitos - e da importância da experiência que é preciso dar ao que os sujeitos denominam jogo é o americano Tobin (1997). Mais importante que o nome conferido ao jogo - brincadeira - e do que as categorizações dos brinquedos é saber o que as crianças estão pensando enquanto estão brincando ou jogando.

Na pesquisa, diz esse autor, nós necessitamos de entrevistas, de técnicas, de métodos que possam compreender os espíritos que estão jogando... O que podemos fazer? Observar... Precisamos conversar com as crianças. Elas têm muito a nos ensinar, a ver coisas importantes que nos façam penetrar no mundo da ciência. (TOBIN, 1997, p. 56).

No intuito de nos aproximar do que realmente é o brinquedo e a brincadeira e as prováveis diferenças entre os dois termos, depois de ter lido gente autorizada a respeito do assunto, buscamos das próprias crianças aquilo que observamos e ouvimos das professoras de crianças pequenas, numa contribuição, aqui posta, como um reforço teórico a partir do empírico.

\section{DA PESQUISA FEITA - O MÉTODO}

O método, segundo Lakatos e Marconi (2010, p. 65), "é um conjunto das atividades sistemáticas e racionais que, com maior segurança e economia, permite alcançar o objetivo - conhecimentos válidos e verdadeiros - traçando o caminho a ser seguido, detectando erros e auxiliando as decisões do cientista"; e se para Cervo e Bervian (2002, p. 23-5) não criamos um método, porque ele está intrinsecamente ligado ao assunto da pesquisa, considerando que a investigação brota do problema de eleição, por isso o uso desse conjunto de etapas de que se serve o método científico, para fornecer subsídios necessários na busca de um resultado para as questões norteadoras da pesquisa, estimulará o nascimento desse caminho que ajudará o pesquisador a realizar tal investigação, a desvelar seus mistérios e a produzir suas constatações, inspiradas pelas hipóteses de trabalho.

Foi se pautando por estas assertivas que entramos em campo, com - um método - ou critérios para a busca da explicação das questões ou dos problemas específicos, descritos no que seriam as brincadeiras vistas e feitas pelas professoras de crianças miúdas - da educação infantil. 
Supondo que o brincar é o ato de manifestação da ludicidade, exercida por homens e animais filhotes, que envolve o ser brincante, que o brinquedo seria todo o material ou as "coisas" que se utilizam como objeto para brincar, e que a brincadeira seria essa atividade simulada por nossa imaginação, "entramos em campo" com o objetivo cardeal de investigar a cultura do brinquedo e da brincadeira pela percepção das professoras da rede municipal da baixada cuiabana, enquanto professoras da primeira etapa, Educação Infantil, do Ensino Básico, e enquanto alunas da disciplina Brinquedos e Brincadeiras no cotidiano da Educação Infantil, sob a nossa batuta.

Em sua ementa, essa disciplina reza pelas seguintes temáticas: "O brincar como eixo curricular e sua prática no cotidiano da educação infantil"; "o brincar e suas teorias"; "a brincadeira na infância em diferentes abordagens: filosofia, antropologia, psicologia e sociologia da infância"; "o brincar como forma própria de a criança significar e apreender o mundo"; "brincadeira e construção de conhecimento"; "Brincadeira como experiência de cultura"; "brincadeira e culturas infantis"; "jogo, brinquedo e brincadeira: definições e questões"; "a ludicidade como mediadora da ação da criança"; "as culturas infantis na contemporaneidade e o repertório de brinquedos, brincadeiras e práticas lúdicas ao longo da história"; "os espaços e tempos do brincar em creches e pré-escolas".

Para tanto, aplicamos um questionário semiestruturado (questões em anexo) com as participantes da disciplina e, com os dados coletados, identificamos a noção que as professoras têm de brincadeira e o modo como desenvolvem esta atividade no ambiente escolar. De modo particular, foi possível analisar as formas de envolvimento e intervenções dessas profissionais no momento da brincadeira das crianças. Atividades práticas nas aulas da disciplina. Como atividades práticas, propusemos e realizamos as seguintes brincadeiras: construção de brinquedos cantados; brincadeiras de roda, brincadeiras com o uso do corpo sem materiais; e algumas intelectivas como Jan-Ken-Pô2. O "Resta Um” é um quebra-cabeça no qual o objetivo é, por meio de movimentos válidos, deixar apenas uma peça no tabuleiro. No início do jogo, há 21 peças no tabuleiro, dispostas com seis, cinco, quatro, três, duas e uma peça, a formar um triângulo retângulo ou escaleno. Um

\footnotetext{
2 Para saber mais sobre este jogo infantil - funcionamento, história e curiosidades -, basta consultar o endereço eletrônico. Disponível em: https://pt.wikipedia.org/wiki/Pedra,_papel_e_tesoura. Acesso: 24 maio 2021.
} 
movimento consiste em pegar uma peça e fazê-la "saltar" do tabuleiro, mexendo-se na horizontal (quantas peças quiser) ou na vertical (apenas uma por vez), deixando os espaços em vazio. A peça que foi "saltada" é retirada do tabuleiro. O jogo termina quando restar apenas uma peça. O jogador vence se deixar no tabuleiro uma única peça.

Como havíamos trabalhado as rubricas do jogo e da brincadeira segundo a obra Os jogos e os homens: a máscara e a vertigem, de Caillois (1990), sugerimos que todas as atividades que aplicamos em sala fossem "banhadas" ou "molhadas", de molho com essa teoria para que as professoras percebessem a serventia daquilo que chamamos de pressupostos teóricos, num exercício acadêmico de enxergar a teoria na prática e a prática com a teoria, e para que tentassem, numa alegoria, irrigar a prática de cada uma.

\section{RESULTADOS - SIGNIFICAÇÕES E INTERAÇÕES DAS PROFESSORAS COM AS BRINCADEIRAS INFANTIS}

Passamos, nesta seção, a mostrar aquilo que pode caracterizar-se como o trato cotidiano dessas professoras e suas relações com as crianças da pré-escola ou creche, enquanto tais, no uso de brinquedos, brincadeiras e jogos. Este primeiro momento de descrição resulta da escuta de 30 dos 60 professores em exercício nessas unidades escolares, o que quer dizer as vozes da metade de todas as que se encontram "regendo classes" - que aqui chamaremos de "alunas-professoras" -, todas responsáveis pelas aulas de Educação Infantil - que chamaremos de "professoras de pré-escola" e que terão a sua identificação com um nome fictício, num acordo com todas elas que colaboraram com a investigação e que bem podem representar todas as professoras e os professores das unidades de pré-escolas da rede cuiabana de ensino da Educação Infantil.

Mostramos essas vozes na forma de seus fragmentos mais reveladores e materializados no papel, a fim de serem enxergados e juntados aos comentários tirados da observação assistemática do grupo em sala de aula do curso, seja nas horas das brincadeiras, seja no momento de construção dos brinquedos. Com base no que vimos mostrar, supomos ser possível caracterizar o cotidiano das professoras dessa "fatia" escolar, caracterizando, ao mesmo tempo, do ponto de vista das participantes, os brinquedos e as brincadeiras de sala e os de curso, 
assim como as relações existentes entre um brincar da escola para ensinar e um brincar do curso para aprender.

\section{O QUE ALEGORIZAM SUAS NARRATIVAS NOS DISCURSOS E NAS PRÁTICAS}

Ficamos à vontade com a acepção da palavra alegoria assumindo com a etimologia do termo aquilo que o dicionarista Houaiss (2007) trata como o modo de expressão para representar pensamentos, ideias sob a forma figurada. Alegoria, também como dizer outra coisa além do sentido literal das palavras ou "significação encoberta", naquilo que ela representa na sua função estética, muito mais que uma interpretação exegética, como fazem os textos sagrados.

São sagrados para nós as falas, as percepções, as noções e o trabalho das professoras quando envolvem a aquisição de brinquedos e brincadeiras, que, apesar e além do sentido literal, pode representar outra coisa no sentido metafórico, assim como fazem as crianças quando se travestem de lobos, monstros, ogros e fadas. Desse modo particular, as brincadeiras feito máscaras podem pôr em cena o nosso lado mais burlesco, caricato, mas também mais generoso. É com essa ambiguidade que as professoras encaram com seu trabalho, aquilo que os jogos, os brinquedos e as brincadeiras podem oferecer.

É muito comum quando professores de pré-escola dizem sobre a usança de jogos, brinquedos e brincadeiras de crianças, em seu métier, o destaque à palavra importância, quase sempre acompanhada de uma utilidade na presença desses pré-textos enquanto estratégias, ou como o Método. Não é incomum também anexarem à palavra importância uma outra tão surrada quanto esta: o desenvolvimento. Desse modo, com a hibridação desses dois vocábulos, chegamos à locução obsessiva na cultura escolar quando esta se dirige à função de ser importante porque ajuda no desenvolvimento de seus alunos. Embora essas mesmas professoras, às vezes, esqueçam-se de que a palavra e a função carregam uma complexidade porque não é tão fácil nem de se perceber e muito menos de se explicar como isso pode ocorrer no curso do crescimento de um indivíduo, o brincar pode ser mais que importante; pode requerer mais que manipular brinquedos; pode ir além do desenvolvimento; pode esconder ou mascarar, com a licença de cada alegoria, algo que esteja subterrâneo. Não é incomum os alunos, 
muitas vezes, simularem prestar atenção às aulas, quando seu corpo já está catapultado no recreio ou nas aulas lá da quadra.

Há teoristas que, quando tratam da função dos jogos, elegem uma matriz psicogenética, porque esta supõe que os nossos genes são capazes de carregar informações seletivas e de endereçar a outras gerações de modo natural. Um exemplo clássico seria quando uma criança aprende a jogar algum jogo sem nunca ter jogado. As informações atávicas auxiliam na aquisição dessa aprendizagem. Outros assumem que isso só é possível no curso das interações que os indivíduos estabelecem com o meio ambiente e com as pessoas e objetos de seu entorno, de modo objetivado - no caso da escola - ou de modo aleatório - na vida cotidiana.

Não importa, basta que exista uma escola e lá estarão os jogos, os brinquedos e as brincadeiras, que se resumirão em atividades lúdicas, porque a criança, dizendo de um jeito simples, precisa, merece e tem o direito de brincar. Mas nunca se fala de privilégios porque são "filhotes", assim como qualquer mamífero que têm muita energia para gastar.

Do questionário (para o questionário utilizado, foram formuladas essas questões, mas, para este texto, utilizaremos apenas aquelas que respondem aos discursos e às práticas de intervenções: o que significa brincar para você? O que representa o brincar para a criança? Você faz intervenções quando as crianças estão brincando? Quando você era criança, costumava brincar de quê? Você costuma brincar com seus alunos? De quê? Qual é a brincadeira que você percebe que as crianças mais gostam de brincar com você? Você utiliza brinquedos?) que aplicamos a essas professoras, foi possível extrair algumas respostas que nos serviram de categorias de análise. Vamos nos concentrar, por eleição, nas narrativas que remetem ao discurso de ser importante e das práticas de intervenções que ajudam no desenvolvimento das crianças.

\section{DISCURSO SOBRE A IMPORTÂNCIA}

O brinquedo, segundo essas professoras, carrega o potencial de enriquecer o mundo infantil, de desenvolver habilidades, criatividade e autonomia. Serve também como fuga das atividades em que as crianças devam fazer sentadas, o que facilita na manutenção do controle. Transforma o ambiente, transportando as crianças para a "terra" do faz de conta, para um ambiente de "magia" propício à 
aprendizagem. O ambiente se torna mais agradável, divertido e alegre. Contribui para um bom relacionamento entre professor e aluno nas relações interpessoais e é excelente forma de imprimir na criança o respeito às regras, necessário para a brincadeira e para a vida. Não se esquecendo sempre de adotar o brinquedo mais adequado para cada faixa etária e incentivar as crianças ao cuidado com o brinquedo. As falas abaixo podem melhor dizer o que a análise suscita:

É muito importante porque respeita a criança pelo simples fato de ser criança, deixando assim um ambiente menos formal e mais acolhedor. (Profa. Carmem - 25 anos).

O brinquedo é algo que as crianças gostam... aprendem como dividir, ter cuidado e sabem como usar no momento certo... É uma ferramenta que pode ser usada como um recurso na Educação Infantil. (Profa. Vera - 35 anos).

O brinquedo no ambiente escolar [...] Ihes dá a liberdade de viajar na imaginação. (Profa. Helena - 27 anos).

[...] sua imaginação trabalha o seu raciocínio lógico e o seu intelecto. Onde a criança é livre para criar e recriar. (Profa. Denise -30 anos).

[...] é através dele que a criança apreende e aprende sobre o mundo em que vive. (Profa. Marcela - 33 anos).

[...] o brinquedo dá vida ao ambiente escolar e estimula a imaginação das crianças. (Profa. Jaciara - 30 anos).

Uma outra categoria nos foi necessária para registrar o que elas, as professoras, consideram como intervenção e que nós, por opção, preferimos nominar de suas práticas. Ao serem questionadas sobre fazerem intervenções quando as crianças estão brincando, as professoras responderam, na maioria, que fazem; às vezes; raramente; sempre; e há aqueles que preferem não fazer intervenção alguma.

Quanto ao tipo de intervenções, foram citadas algumas formas de explorar situações para estimular o desenvolvimento dos alunos, incentivar e encorajá-los a ter atitudes e inciativas de como potencializar a afetividade. Uma grande parte dos professores se posiciona sobre a necessidade de resolver conflitos que ocorrem antes, durante e após o brincar, julgam que há situações em que seus alunos não são capazes de resolver, resolução também eficiente quando desrespeitam as regras preestabelecidas. 
Alguns consideram o momento do brincar como primordial e apenas tomam a atitude de observar. Outros já dizem interferir, quando convém, sem atrapalhar a brincadeira, para fazer perguntas pontuais e pertinentes ao contexto brincante. Há também um grupo de professores que apenas interferem quando pressentem uma iminente agressividade entre as crianças ou o risco de acidentes físicos.

A professora Marisa diz se preocupar quando as crianças fazem das peças de montar armas de brincar. Alega intervir e orientar para que essas condutas sejam evitadas, pois, para ela, "não é uma brincadeira legal", isto é, do bem, já que, em sua visão, "arma não é brinquedo". A professora Nazaré responde quando se dá sua intervenção: "Quando é necessário, nas resoluções de conflitos ou quando a atividade é direcionada, para alcançar os objetivos planejados, de forma sutil para não estragar a brincadeira [...]". Assim como Nazaré, algumas das profissionais responderam o questionário mencionando a categoria de atividades dirigidas ou direcionadas. Abaixo, algumas das falas que mostram como são esses tipos de intervenções:

Às vezes. Quando surge conflito entre eles, na disputa pelo mesmo brinquedo ou quando é necessário fazer uma mediação para estipular regras. (Profa. Rosa -30 anos).

Poucas vezes. Quando há briga por um determinado objeto e quando a atividade que estamos desenvolvendo pede. (Profa. Paula - 29 anos).

Às vezes. Entro na brincadeira, por ex.: duas crianças brigavam porque o coleguinha queria o mesmo pedaço do bolo de chocolate, então entrei na brincadeira e falei "Amiguinha, porque não troca o bolo de chocolate por bolo de abacaxi?". E resolveu a questão. (Profa. Maria - 25 anos).

Há, ainda, professoras que preferem uma intervenção na brincadeiras e nos jogos, mas a propósito naquilo que podem escoar a uma outra alegoria, voltada à construção ou mesmo a uma viagem as suas reminiscências.

Às vezes. Eu proponho às crianças algumas brincadeiras que foram da minha infância... uma brincadeira mais simples e sutil, que não seja muito elaborada. (Profa. Luzia - 30 anos).

Às vezes. Quando noto que posso acrescentar algo na brincadeira faço intervenções, por exemplo, quando estão brincando de carrinhos e um quebra, eu falo "Podemos construir uma oficina?" etc. (Profa. Nair - 30 anos). 
Como se vê, as intervenções são para resolver os problemas ligados à agressividade ou alguma forma de violência, mas há aquelas, em minoria, que intervêm propondo um acréscimo na atividade, mudando a sua rota, sem se desgrudar da intenção maior da escola: estar à cata de novos conhecimentos.

\section{CONSIDERAÇÕES FINAIS}

As alegorias na forma de escrita, fala e ação das professoras nos conduziram a alguns desvelamentos sobre brinquedos e brincadeiras de crianças, sob o manto pedagógico do discurso e da prática.

Com o mantra sobre a importância do brinquedo, dos jogos e das brincadeiras no ambiente escolar, foi possível observar que os participantes os consideram essenciais, quando afirmam que estimulam a aprendizagem, auxiliam no processo de alfabetização, além de servirem para: entreter, descontrair a criança, trazer prazer e alegria, desenvolver a flexibilidade motora, a oralidade, a criatividade, os aspectos emocional, afetivo e a fantasia.

O brinquedo figura como suporte, como motivação para a descoberta do outro e de si mesmo, favorece a interação social, a socialização, a manipulação de objetos novos, propicia combinações de ideias quando estimula a criança a aprender a compartilhar, a dividir e a cooperar de livre e espontânea vontade, sem aquela obrigação moralista do dever ser.

Nenhuma das entrevistadas enxergam uma oposição entre o divertimento estéril e a instrução. Manson (2002, p. 242) descreve que os pedagogos iluministas alertavam para esse antagonismo entre brincar e estudar. Ratifica esse autor que "nas obras pedagógicas como nos livros para a juventude, exprime uma hierarquia de valores, onde o estudo leva a melhor sobre a brincadeira". Os autores contemporâneos de Rousseau recomendavam que ajudássemos as crianças a não ter repulsa pelo estudo, porque é feito de sacrifícios, mas que, por outro lado, não deveríamos "esconder os esforços necessários sob o manto falacioso e encantador do jogo" (MANSON, 2002, p. 242).

As intervenções das professoras nos ensinaram, de modo peculiar elas as fazem, mas, quando lemos detidamente suas falas, a alegoria relevante dá-se na diligência policial, mais que na intervenção pedagógica. Estão mais preparados a intervir para dissolver conflitos do que para a mediação de situações litigiosas 
ou, quem sabe, apresentar uma sugestão para outros caminhos que trariam uma nova energia.

São raros os professores que sugerem um desenho, uma fotografia, uma filmagem ou outra mídia tendo como mote os brinquedos e as brincadeiras, assim como são raros os professores que brincam com eles; que tentam extrair uma pauta para assuntos relevantes ou que proponham uma discussão de gênero, diversidade, precariedade do espaço escolar, a partir dos episódios litigantes que venham a irrigar uma conduta de risco.

Os professores intervêm para uma contenção, que nada tem a ver com a preservação e estimulação do ambiente lúdico. O que não significa que as crianças não devam ter um olhar de alguém que as cuide, nem tão pouco que se faça vistas grossas às possibilidades de incidentes que podem ocorrer nestes espaços brincantes. Porque as crianças, movidas por seu espírito lúdico, muitas vezes se põem em ciladas ou em situações de risco.

São raras, mas pelas vozes há espaço para intervenções criativas destes profissionais, quando são capazes de captar as situações de brincadeiras que se apresentam nos grupos infantis e aos poucos inserir objetos, brinquedos, ideias ou músicas, imiscuindo-se eles mesmos nas situações brincantes, de forma a tornar-se, assim, mais um brincador.

Por fim, nota-se que os discursos sobre os brinquedos e as brincadeiras na educação infantil denotam que os professores trazem em suas memórias narrativas lúdicas infantis e tentam, em algumas situações, reproduzir, com seus alunos, as brincadeiras que conhecem desde criança.

\section{REFERÊNCIAS}

BENJAMIN, Walter. Reflexões: a criança, o brinquedo, a educação. São Paulo: Summus, 1984.

BROUGÈRE, Gilles. Jeu et Éducation. Paris: Harmattan, 1995.

CAILLOIS, Roger. Les jeux et les hommes: le masque et le vertige. Paris: Gallimard, 1967.

CASCUDO, Luís da Câmara. Dicionário do folclore brasileiro. São Paulo: EDUSP, 1988.

CERVO, Amado L.; BERVIAN, Pedro A. Metodologia científica. 5. ed. São Paulo: Prentice Hall, 2002. 
CHÂTEAU, Jean. O jogo e a criança. São Paulo: Summus, 1987.

HOUAISS, Antônio; VILLAR, Mauro de Salles. Dicionário Houaiss da Língua Portuguesa. Rio de Janeiro: Objetiva, 2007.

HUIZINGA, Johan. Homo Ludens: o jogo como elemento da cultura. São Paulo: Perspectiva, 1990.

LAKATOS, Eva M.; MARCONI, Marina de A. Fundamentos de metodologia científica. 7. ed. São Paulo: Atlas, 2010.

MANSON, Michel. História do brinquedo e dos jogos: brincar através dos tempos. Lisboa: Teorema, 2002.

SUTTON-SMITH, Brian. The ambiguity of play. Cambridge: Harvard University Press, 1997.

TOBIN, Joseph Jay. Making a place for pleasure in Early Childhood Education. New Haven: Yale University Press, British Library, 1997.

\section{Sobre o autor:}

Cleomar Ferreira Gomes: Pós-doutor em Socioantropologia da Educação pela Universidade Federal Fluminense (UFF). Doutor em Educação pela Universidade de São Paulo (USP). Mestre em Educação pela Universidade Federal de Mato Grosso (UFMT). Especialização em Ciências do Jogo pela Université de ParisNord, Villetaneuse/Paris. Especialização em Fundamentação Filosófica da Educação Física (UFMT). Licenciado em Educação Física, pela Universidade Federal de Mato Grosso (UFMT). Atualmente, é professor titular da UFMT. E-mail: gomescleo.cg@gmail.com, Orcid: http://orcid.org/0000-0003-0451-1011

\section{Recebido em: 11/04/2019} Aprovado em: 01/02/2021 